\title{
PENGARUH KECEPATAN PENGADUKAN PROSES RHEOCASTING TERHADAP STRUKTUR MIKRO DAN FLUIDITAS PADUAN AI-Cu
}

\author{
Muhammad Rezki Fitrì \\ Putra \\ Mahasiswa \\ Universitas Brawijaya \\ muh.rezkifp@gmail.com
Wahyono Suprapto
Tenaga Pengajar (Dosen)
Universitas Brawijaya
Jurusan Teknik Mesin
wahyos@ub.ac.id \\ Achmad As'ad Sonief \\ Tenaga Pengajar (Dosen) \\ Universitas Brawijaya \\ Jurusan Teknik Mesin \\ sonief@ub.ac.id
}

Rheocasting with the aim of developing and offering solutions to problems related to the casting process. Rheocasting is a casting process that utilizes solidification agitation to change the dendritic structure to non-dendrite (globular) by giving a variation of the stirring speed. Al-Cu is a metal material that has high strength-toweight ratio characteristics from steel, good fatigue resistance, and heat-treatable. But fluidity is low, this triggers casting defects such as shrinkage and miss-run. The defect occurs because the cooling process of liquid metal is not uniform or there is gas trapped in molten metal. Defects in casting can significantly reduce material mechanical properties. The results show morphological changes in the dendrites to rosette to globular with increased stirring speed and grain diameter decreasing with increasing stirring speed. Increasing the stirring speed also produces a positive trend of the fluidity value of $\mathrm{Al}-\mathrm{Cu}$ alloys in each mold thickness.

Keywords: Rheocasting, $\mathrm{Al}-\mathrm{Cu}$, Stirring Speed, Fluidity, Microstructure

\section{PENDAHULUAN}

Rheocasting bertujuan untuk mengubah struktur logam dendritik menjadi non dendritic (globular) [1]. Ketidakhadiran struktur dendrit menghasilkan sifat-sifat coran terutama sifat mekanik yang lebih baik, dengan terjadinya penghalusan butir logam menjadi lebih pejal, dan boleh dikatakan bebas dari rongga udara dan rongga penyusutan [2]. Proses rheocasting menggunakan temperatur peleburan yang rendah juga dapat memperpanjang umur cetakan, kualitas pada produk coran meningkat [3]. Kualitas produk coran meliputi geometri bentuk, efesiensi produk coran, kekarasan permukaan, densitas produk, dan sifat mekaniknya meningkat [4]. Rahimi et al menerapkan teknik rheocasting untuk paduan Al-2024, logam cair menggunakan impeller grafit. Hasilnya ukuran butiran menjadi halus sehingga meningkatkan kekerasan dan kekuatan tekan seiring dengan peningkatan kecepatan pengadukan [5]. Dalam industri otomotif komponen suku cadang maupun elemen-elemen mesin banyak menggunakan paduan aluminium dengan proses pengecoran [6]. Penggunaan paduan aluminium pada pengecoran salah satunya aluminium dengan tembaga (Al-Cu), memiliki high strength-to-weight ratio (pada kondisi T6: $465 \mathrm{~N} / \mathrm{mm}^{2}$ atau spesifik ketangguhan mencapai 167 N.m/kg). Paduan ini juga memiliki ketangguhan dan ketahanan lelah yang baik, serta heat-treatable [7]. Paduan $\mathrm{Al}-\mathrm{Cu}$ biasanya digunakan pada struktur pesawat, produk mesin skrup, paku keling, dan instrumen ilmiah pada kedokteran hewan dan ortopedi [4, 8]. Seiring berjalannya waktu Al-Cu dilupakan para peneliti atau rekayasawan, karena rendahnya mampu alirnya (fluidity), kelemahan tersebut mengakibatkan rentang waktu pengisian yang panjang, sehingga memicu cacat pada produk coran yaitu porositas [9]. Salah satu parameter yang berpengaruh dari kualitas produk coran adalah sifat mampu alir (fluidity) yang baik, sehingga logam cair dapat mengisi cetakan sepenuhnya. Umumnya ada dua metode untuk mengolah paduan $\mathrm{Al}-\mathrm{Cu}$ proses tempa dan proses casting [10]. Namun biaya proses tempa sangat tinggi dibandingkan dengan proses pengecoran, dan sebaliknya proses pengecoran menghasilkan struktur dengan cacat coran seperti pori dan rongga penyusutan 
[11]. Dengan permasalah tersebut diperlukan proses pengecoran yang sesuai untuk meningkatkan fluiditas dan mereduksi cacat coran. Dengan demikian proses rheocasting mungkin merupakan metode terbaik untuk mereduksi kelemahan dari paduan $\mathrm{Al}-\mathrm{Cu}$. Pada studi ini menerapkan metode rheocasting untuk dalam pengecoran paduan $\mathrm{Al}-\mathrm{Cu}$ secara eksperimen sehingga dapat diamati secara langsung fenomena yang terjadi dan mengetahui nilai fluiditas dan perubahan sturuktur mikro dari paduan setelah diamati dengan mikroskop optik. Maka dari itu penelitian secara eksperimen ini nantinya perlu dikembangkan sebagai bentuk pencarian variabel yang tepat dalam proses rheocasting, dan dapat memotivasi riset selanjutnya dalam meningkatkan produktifitas dari proses manufaktur logam khususnya untuk paduan $\mathrm{Al}-\mathrm{Cu}$.

\section{METODE DAN BAHAN}

Bahan yang digunakan dari proses ini plat alumunium dan tembaga daur ulang yang sudah dalam bentuk ingot $\mathrm{Al}-\mathrm{Cu}$. Selanjutnya ingot dari paduan Al-Cu di uji dengan spectrometry untuk mengetahui nominal komposisi kimianya. Komposisi kimia Al-Cu dapat dilihat pada Tabel 1.

Tabel 1. Komposisi Kimia Al-Cu wt\%

\begin{tabular}{c|c|c|c|c|c|c|c}
\hline $\mathrm{Al}$ & $\mathrm{Cu}$ & $\mathrm{Fe}$ & $\mathrm{Si}$ & $\mathrm{Mn}$ & $\mathrm{Zn}$ & $\mathrm{Mg}$ & $\mathrm{Ni}$ \\
\hline 92,4 & 7,06 & 0,33 & 0,094 & 0,070 & 0,013 & 0,009 & 0,006 \\
\hline
\end{tabular}

Sebelum proses peleburan ingot $\mathrm{Al}-\mathrm{Cu}$ ditimbang menggunakan timbangan digital seberat 500 gr. Tahap pertama ingot dimasukan kedalam ladel tembikar yang diletakan didalam tungku listrik. Sebelum dituang cetakan dipanaskan hingga mencapai suhu $250{ }^{\circ} \mathrm{C}$. Suhu peleburan $700{ }^{\circ} \mathrm{C}$, pada tahap ini logam cair suhu tungku diturunkan mencapai $670{ }^{\circ} \mathrm{C}$ (sekitar $15^{\circ} \mathrm{C}$ diatas suhu liquid) diaduk dengan berbagai kecepatan aduk dari 900-1500 rpm dengan batang pengaduk dibandingkan dengan tanpa diaduk $0 \mathrm{rpm}$. Skema proses Rheocasting dapat dilihat pada Gambar 1.

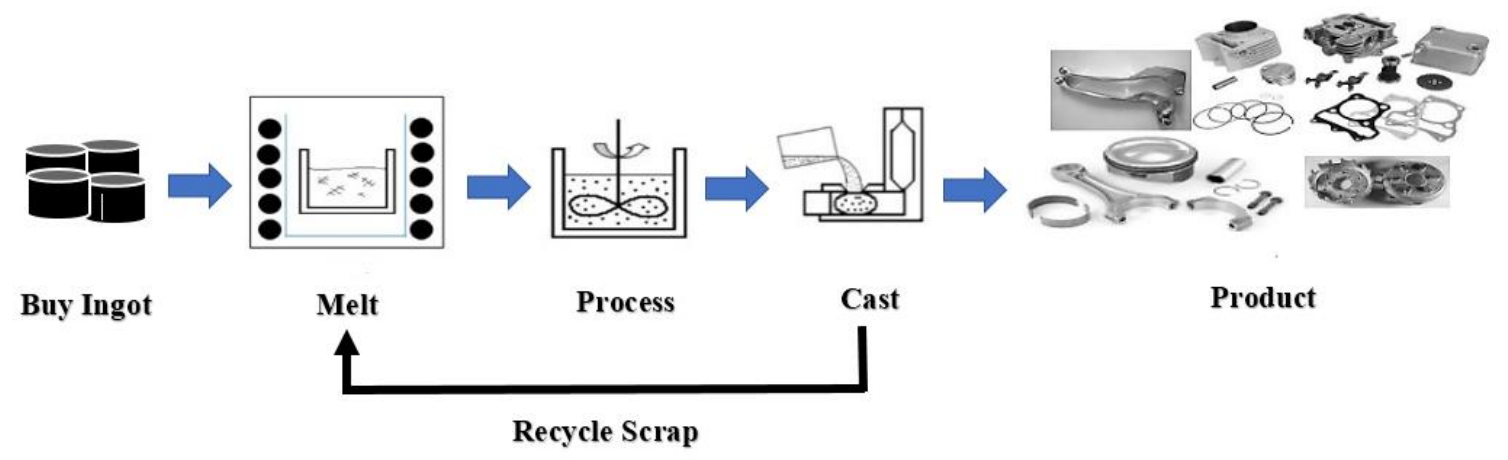

Gambar 1. Proses Rheocasting

\subsection{Analisa struktur mikro}

Sampel yang digunakan hasil dari potongan produk yang dituang dan sudah diamplas halus mengunakan amplas dengan grid \#90 sampai dengan \#1500 pada permukaan yang ingin diamati. Analisa mikrostruktur menggunakan prosedur Keller Etching Reagen ( 2 mL HF, 3 mL HCl, 5 mL HNO3, dan 90 mL H2O) selama 15 detik dengan mikroskop optik [12].

Dari mikrostruktur dapat diketahui juga rata-rata ukuran butiran menggunakan metode planimetri yang dikembangkan oleh Jeffries, yang mana menetukan jumlah butir dari luasan yang dapat dihubungkan pada standar ukuran butir ASTM E112, dan jumlah butir yang terdapat dari luasan area yang dinotasikan sebagai NA [13].

$$
\begin{aligned}
& \mathrm{NA}=\mathrm{f}\left(N_{\text {inside }}+1 / 2 N_{\text {intercepted }}\right) \\
& \mathrm{G}=\{3.322(\log 10 \mathrm{NA})-2.954)
\end{aligned}
$$


Dimana $\mathrm{N}_{\text {inside }}$ jumlah butir bagian dalam dan $\mathrm{N}_{\text {intercept }}$ dan yang bersinggungan dengan lingkaran area, $f$ faktor pengali Jeffries, dan G adalah ASTM grain size number. .

\subsection{Fluidity test piece}

Pengujian empiris telah digunakan untuk mengukur nilai fluiditas. Hal ini didasarkan pada kondisi yang menyerupai pengecoran logam dan pengukuran fluiditas didefinisikan sebagai total jarak yang dilalui cairan logam dalam sistem saluran tertutup seperti yang ditunjukkan pada Gambar 2. Pengujian yang paling umum digunakan untuk mengetahui sifat fluiditas paduan aluminium tuang adalah alat uji fluiditas cetakan spiral dan uji fluiditas vakum [7].

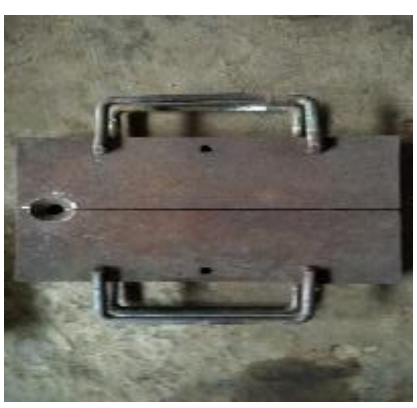

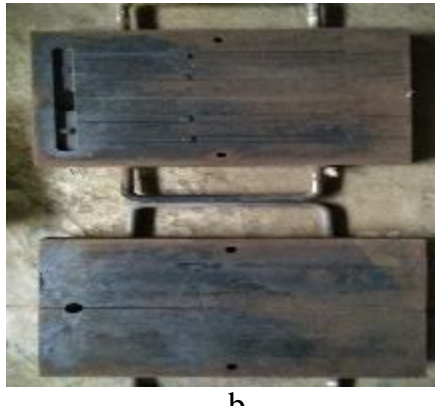

b

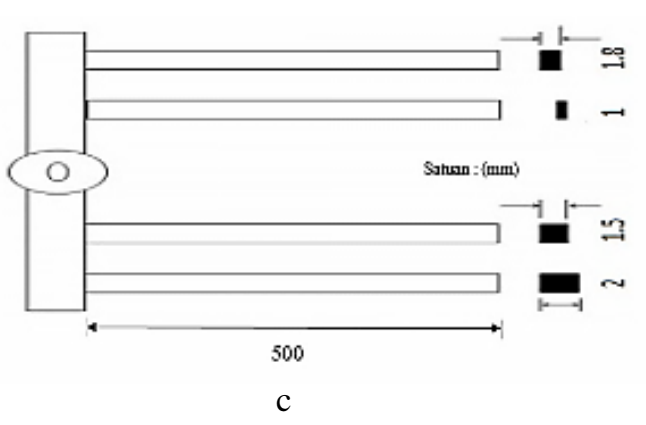

Gambar 2. Metode Fluidity Test Piece, a) cetakan tertutup, b) cetakan dibuka, c) gambar kerja cetakan

Pengujian mampu alir (fluidity) menggunakan metode pengujian dengan fluidity test piece. Jenis pengujian ini banyak digunakan saat ini dan telah dikembangkan oleh Universitas Birmingham UK. Metode pengujian fludity test piece, didapatkan panjang logam cair yang mengalir dari berbagai macam ketebalan cetakan. Melalui analisis ini juga dapat diketahui seberapa tipis ketebalan yang dapat dilalui logam cair saat penuangan. Dengan demikian semakin tipis cetakan yang dapat dilalui logam cair maka fluiditas dari material semakin baik $[4,11]$.

\section{HASIL DAN DISKUSI}

\subsection{Analisa Mikrostruktur}

Hasil struktur mikro dari paduan Al-Cu di uji dengan mikroskop optik yang diproses dengan rheocasting dari berbagai kecepatan disajikan pada Gambar 3. Dalam hal ini kecepatan pengadukan berperan penting dalam pembentukan struktur globular dari rheocasting. Gambar 3a menunjukan struktur dari paduan dengan pengecoran tanpa pengadukan (konvensional) atau tanpa adanya aplikasi gaya geser selama proses solidifikasi. Dilihat struktur menghasilkan sepenuhnya dendrit dan memiliki beberapa pori. Dengan proses rheocasting dengan pengadukan mekanis strukturmikro yang mulanya dendrit bertansformasi menjadi globular yang ditunjukan pada Gambar 3b-3e. Dalam tahap ini batang pengaduk dimasukan dalam paduan aluminium cair yang memiliki suhu sedikit diatas temperatur cairnya. Kemudian batang pengaduk diputar dengan kecepatan yang telah ditentukan, hingga pada temperatur dibawah titik cair dari paduan. Nukleasi struktur yang dihasilkan memungkinkan terjadinya struktur yang mendekati globular dikarenakan adanya konveksi paksa akibat gaya geser dari batang pengaduk terhaap logam cair, mengakibatkan fragmentasi dendrit dari aluminium cair sehingga menimbulkan butiran yang relatif mendekati bundar. Morfologi struktur dendrit akan bertransformasi menjadi roset dengan memberikan pengadukan pada logam cair. Namun, dengan kecepatan pengadukan yang ditingkatkan morfologi rosete akan berubah menjadi globular [10]. Ketika kecepatan pengadukan ditingkatkan pertumbuhan butiran akan relatif seragam dikarenakan gradien temperatur lebih rendah mengakibatkan pertumbuhan butiran globular jadi merata [15]. 

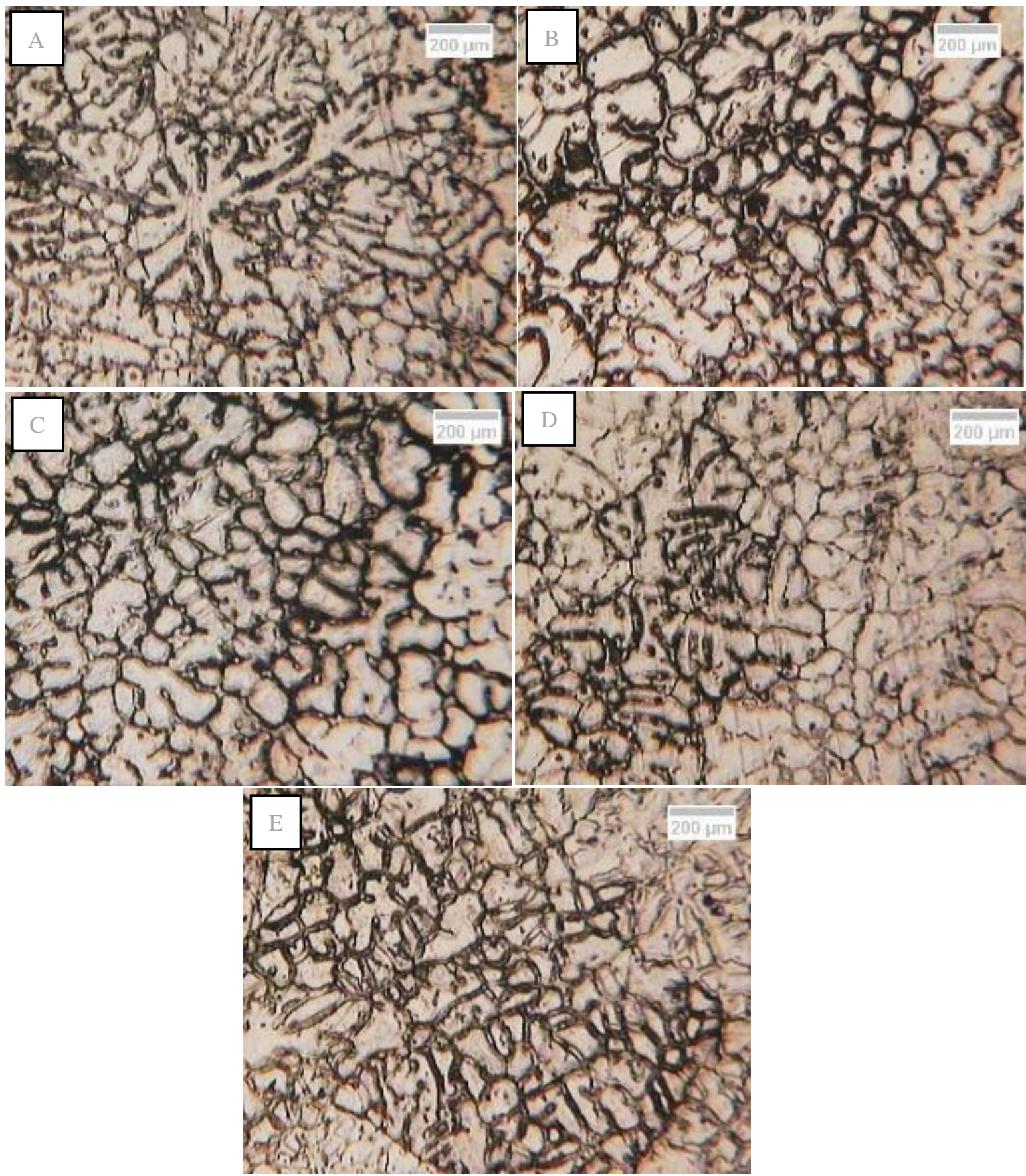

Gambar 3. Stuktur mikro paduan Al-Cu, a) pengecoran konvensional (0 rpm), b) $900 \mathrm{rpm}$, c) $1100 \mathrm{rpm}$, d) $1300 \mathrm{rpm}$, dan e) $1500 \mathrm{rpm}$

Hasil perhitungan ukuran butiran dari proses tanpa pengadukan (konvensional $0 \mathrm{rpm}$ ) dibandingkan dengan proses rheocasting yang diberikan variasi kecepatan pengadukan pada dilihat dari Gambar 4 . Pada 0 rpm didapatkan diameter butiran 37,9 $\mu \mathrm{m}$. Seiring dengan memberikan variasi kecepatan pengadukan dari 900 sampai $1300 \mathrm{rpm}$ mengakibatkan rata-rata penurunan ukuran butir sekitar 16\%. Namun, pada $1300 \mathrm{rpm}$ ke $1500 \mathrm{rpm}$ hanya menghasilkan penurunan ukuran butiran sekitar 5\%. Penurunan ukuran butir dengan meningkatkan kecepatan pengadukan juga telah disampaikan oleh penulis sebelumnya dimana hal ini dikaitakan pada awal fregmentasi dendrit yang tebentuk akibat gaya geser pada logam cair [16]. Akibat adanya penetrasi cepat pada fasa cair mengakibatkan terjadinya dislokasi pada lengan dendrit. Perlu diperhatikan terjadinya dislokasi pada lengan dendrit secara geometris menghasilkan tekukan pada lengan dendrit akibat gaya geser yang terjadi dengan meningkatkan kecepatan pengadukan cabang dendrit yang rusak atau terpotong bertindak sebagai nuklei kristal baru dan menimbulkan penyempurnaan butir partikel primer dari paduan. 


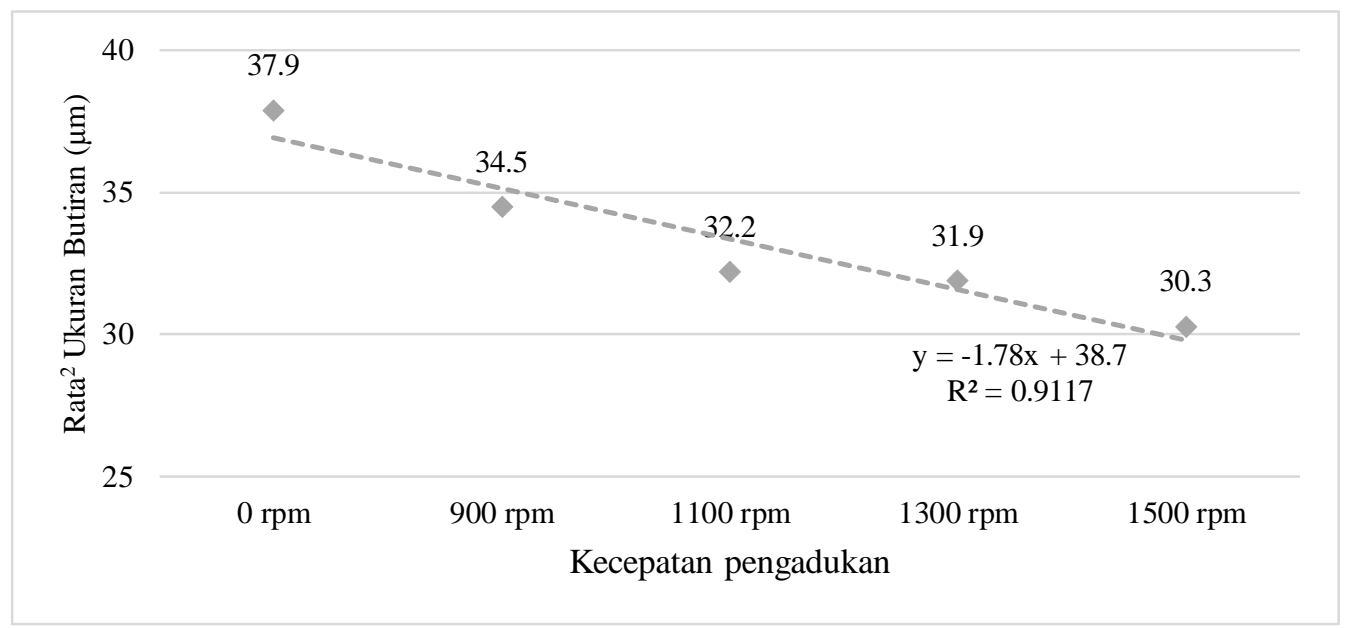

Gambar 4. Pengaruh Kecepatan pengadukan pada diameter butiran proses rheocasting

\subsection{Analisa Fluiditas}

Kemampuan mengalirnya logam cair mengisi seluruh cetakan terutama bagian yang tipis dan mengikuti bentuk cetakan tersebut hingga terjadinya solidifikasi menggambarkan fluiditas logam yang baik. Fluiditas logam berkaitan terhadap sifat mampu cor (castibility) dari suatu logam. Setelah dilakukan proses rheocasting dengan berbagai kecepatan putaran aduk didapatkan nilai fluiditas dari berbagai ketebalan cetakan yang dapat dialiri logam cair hingga membeku. Kemampuan aliran logam cair dalam berbagai saluran cetakan pengujian fluiditas ditunjukkan pada Gambar 5.

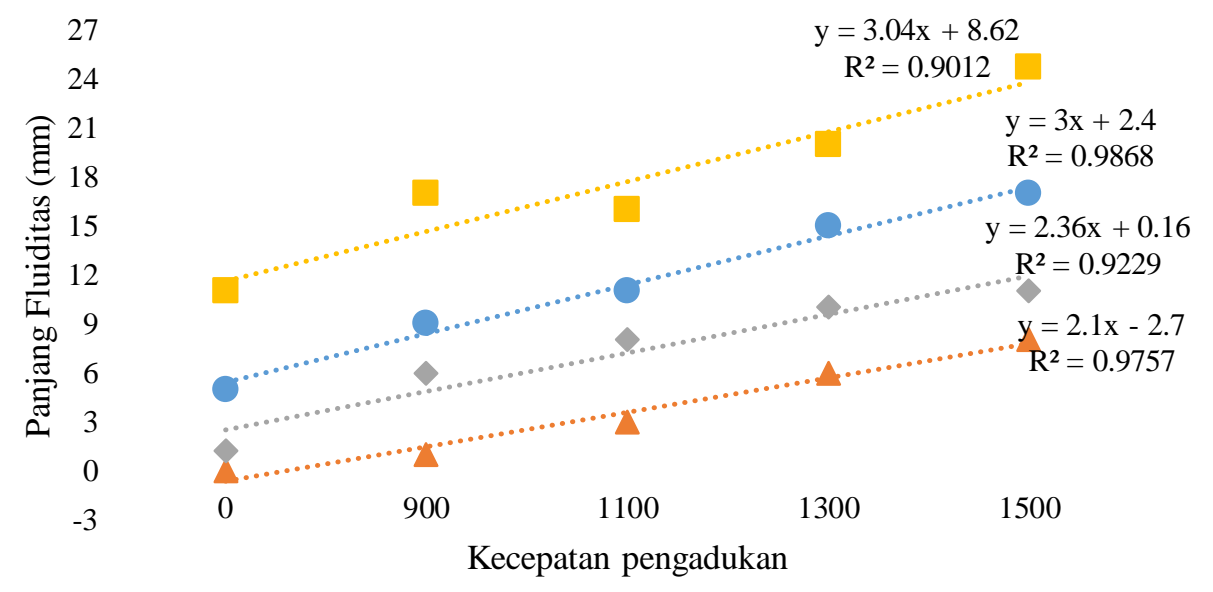

Ketebalan $1,8 \mathrm{~mm} \quad \Delta$ Ketebalan $1 \mathrm{~mm} \quad \diamond$ Ketebalan $1,5 \mathrm{~mm} \quad$ Ketebalan $2 \mathrm{~mm}$

Gambar 5. Hasil Fluiditas Al-Cu Proses Rheocasting

Gambar 5 menjelaskan peningkatan kecepatan pengadukan memberikan karakteristik aliran yang baik. Peningkatan fluiditas yang signifikan terkait erat dengan penyempurnaan butir dari proses rheocasting itu sendiri. Dalam hal ini dimana proses rheocasting memberikan agitasi solidifikasi dalam logam cair mengakibatkan beban geser pada lengan dendrit sehingga lengan dendrit tepotong menjadikan struktur dendritik berubah globular, dengan struktur globular logam cair dapat mudah mengisi rongga cetakan hal ini juga yang memperkuat aliran logam cair dan kemudian mengurangi turbulensi dalam aliran [17]. Dalam putaran aduk 900, 1100 s.d 1500 rpm, peningkatan panjang aliran logam dengan ketebalan cetakan 2 mm; 17 $24(\mathrm{~mm})$ ketebalan 1,8 mm; 9-17 (mm), ketebalan 1,5 mm; 6-11 (mm), dan ketebalan $1 \mathrm{~mm}$; 1-8 (mm). Ketebalan cetakan dapat juga mempengaruhi mampu alir dari logam cair. Cetakan yang tebal memiliki waktu pembekuan yang lebih lama. Ketebalan cetakan $1 \mathrm{~mm}$ mempunyai waktu pembekuan yang cepat sehingga 
terjadi pembekuan lebih awal.

\section{KESIMPULAN}

Peningkatan kecepatan pengadukan berpengaruh signifikan pada perubahan morfologi struktur dendrit menuju globular dari paduan Al-Cu, dan juga pada turunnya diameter butiran paduan. Dari hasil pengujian fluiditas peningkatan kecepatan pengadukan dari rheocasting memberikan tren meningkat pada kemampuan alir dari paduan. Perubahan strukturmikro khususnya ukuran butiran halus dan morfologinya yang mencapai bulat menjadikan paduan mudah mengalir mengisi rongga cetak.

\section{PERNYATAAN TERIMAKASIH}

Terimakasih kepada Penanggung jawab Lab $\alpha \beta \gamma$ metal casting specialist Landungsari, Malang, dan jajaran staf nya, dan terimakasih kepada bapak Ma'ruf., MT.

\section{DAFTAR PUSTAKA}

[1] ZHAO-HUA HU, XIANG PENG, GUO-HUA WU, DA-QIANG CHENG, WEN-CAI LIU, LIANG ZHANG, dan WEN-JIANG DING, "Microstructure Evolution And Mechanical Properties Of RheoProcessed ADC12 Alloy," Trans. Nonferrous Met. Soc. China (English Ed., Vol. 26, No. 12, Pp. 30703080, 2016.

[2] A. POLA, M. TOCCi, dan P. KAPRANOS, "Microstructure And Properties of Semi-Solid Aluminum Alloys: A Literature Review," Metals (Basel)., Vol. 8, No. 3, P. 181, 2018.

[3] A. M. AZIZ, M. Z. OMAR, dan M. S. SALLEH, "Evolusi Mikrostruktur Alloy A333 Melalui Proses Logam Separa Pepejal," Sains Malaysiana, Vol. 45, No. 6, Pp. 977-987, 2016.

[4] W. SUPRAPTO, Teknologi Pengecoran Logam. Malang: Ub Press, ISBN 978-602-432-289-2 2017.

[5] B. RAHIMI, H. KHOSRAVI, dan M. HADDAD-SABZEVAR, "Microstructural Characteristics and Mechanical Properties Of Al-2024 Alloy Processed Via A Rheocasting Route," Int. J. Miner. Metall. Mater., Vol. 22, No. 1, Pp. 59-67, 2015.

[6] P. OSMOND, V. LE, F. MOREL, dan D. BELLETT, "Effect Of Porosity On The Fatigue Strength Of Cast Aluminium Alloys : From The Specimen To The Structure," Procedia Eng., Vol. 213, No. 2017, Pp. 630-643, 2018.

[7] K. YILDIRIM, M. HELVACI, Ö. G, E. ERZI, C. KAHRUMAN, dan D. DISPINAR, "Fluidity Characteristics Of A201 And A206 Al-Cu Alloy," Arch. Foundry Eng., Vol. 18, No. 1, Pp. 135-138, 2018.

[8] B. K. KANG dan I. SOHN, "Effects Of Cu And Si Contents On The Fluidity, Hot Tearing, And Mechanical Properties Of Al-Cu-Si Alloys," Metall. Mater. Trans. A, 2018.

[9] J. ZHANG dan Y. LI, "Effects Of Different Rotation Speeds On Microstructure , Hardness And Corrosion Resistance Of The Au-Cu Alloy," Gold Bull. Springer, Vol. 50, No. 2, Pp. 137-145, 2017.

[10] P. MELALI, P. ASHTIJOO, dan B. NIROUMAND, "Effect Of Stirring Speed And Flow Pattern On The Microstructure Of A Rheocast Al-Mg Alloy,” Assoc. Metall. Eng. Serbia Ames, Vol. Vol 21 (1), Pp. 3543, 2015.

[11] S. RASYID, E. ARIF, H. ARSYAD, dan M. SYAHID, "Effects Of Stirring Parameters On The Rheocast Microstructure And Mechanical Properties Of Aluminum Alloy ADC12," In Matec Web Of Conferences, 2018, Vol. 12004, Pp. 1-5.

[12] R. GUPTA, A. SHARMA, U. PANDEL, dan L. RATKE, "Effect Of Stirring Speed On Microstructure Of A356 Alloy Cast Through Rheometal Process," Int. J. Mater. Res. (Formerly Z. Met., Vol. 108, No. Table 1, Pp. 648-655, 2017.

[13] ASTM INTERNATIONAL, "Standard Test Methods For Determining Average Grain Size," 2014.

[14] K. P. P. PANDEE dan S. B. C. LIMMANEEVICHITR, "Fluidity And Hot Cracking Susceptibility Of A356 Alloys With Sc Additions," Trans. Indian Inst. Met., 2018.

[15] B. ZHOU, Y. KANG, G. ZHU, J. GAO, M. QI, dan H. ZHANG, "Forced Convection Rheoforming Process For Preparation Of 7075 Aluminum Alloy Semisolid Slurry And Its Numerical Simulation," Trans. Nonferrous Met. Soc. China, Vol. 24, No. 4, Pp. 1109-1116, 2014.

[16] L. S. RAO, A. K. JHA, dan S. N. OJHA, "Tribology and Surface Topography Of Al-10cu-Fe Alloy 
Produced By Rheocasting Process,” India, 2017.

[17] S. P. MIDSON, "Industrial Applications for Aluminum Semi-Solid Castings Industrial Applications For Aluminum Semi-Solid Castings," Solid State Phenom., Vol. 217-218, Pp. 487-495, 2016. 